\title{
Role and Effectiveness of Postoperative Voice Therapy in Laryngeal Microsurgery
}

\author{
In Hyo Seo ${ }^{1,2}$, Jeong-Hwan Moon ${ }^{1}$, Phil-Sang Chung ${ }^{1}$, and Sang Joon Lee ${ }^{1}$ \\ ${ }^{I}$ Departments of Otorhinolaryngology-Head \& Neck Surgery, ${ }^{2}$ Voice \& Speech Clinic, College of Medicine, Dankook University, \\ Cheonan, Korea
}

\section{후두미세수술에서 술 후 음성치료의 역할 및 효과}

서인효 ${ }^{1,2} \cdot$ 문정환 $^{1} \cdot$ 정필상 $^{1} \cdot$ 이상준 $^{1}$

단국대학교 의과대학 이비인후-두경부외과학교실, ${ }^{1}$ 음성언어치료실 ${ }^{2}$

\author{
Received September 15, 2017 \\ Revised December 12, 2017 \\ Accepted December 15, 2017 \\ Address for correspondence \\ Sang Joon Lee, MD \\ Department of Otorhinolaryngology- \\ Head \& Neck Surgery, \\ College of Medicine, Dankook \\ University, 201 Manghyang-ro, \\ Dongnam-gu, Cheonan 31116, Korea \\ Tel $+82-41-550-3976$ \\ Fax $+82-41-556-1090$ \\ E-mail1sj72@dankook.ac.kr
}

Background and Objectives Voice therapy is performed following laryngeal microsurgery to help the recovery of the operation site and assist in optimal voice output. The aim of this study was to evaluate the effect of postoperative voice therapy and to obtain objective evidence about the necessity of voice therapy.

Subjects and Method The voice of 109 patients who underwent laryngeal microsurgery for vocal fold lesions and received voice therapy was analyzed. Voice analysis was performed preoperatively, postoperatively, and after the first voice therapy. GRBAS scale was used for auditory perceptual evaluation and acoustic analysis was performed for objective evaluation.

Results Overall, significant improvement was observed postoperatively in both auditory perceptual evaluation and acoustic parameters, and significantly better voice was obtained after the first postoperative voice therapy. The degree of postoperative voice improvement varied on the type of vocal fold lesions, but voice quality was improved in all diseases after first postoperative voice therapy. The number of voice therapy decreased significantly as the voice quality improved after the operation or the first voice therapy. Four or more voice therapy were needed when the cepstral/spectral index of dysphonia (CSID) value was 5.88 or higher. Conclusion Voice therapy following laryngeal microsurgery was effective in better voice output. The CSID value after the first postoperative voice therapy was predictive of finding patients who need long-term voice therapy. These results suggest that the first postoperative voice therapy will be helpful in finding the adequate vocalization method and providing objective evidence for selecting patients who would require continuous voice therapy.

Korean J Otorhinolaryngol-Head Neck Surg 2018;61(4):200-7

Key Words Acoustics $\cdot$ Larynx $\cdot$ Microsurgery $\cdot$ Voice.

\author{
서 론 \\ 후두미세수술의 목표는 병변의 제거를 통하여 음성 기능을 \\ 최대한 회복하는 데에 있다. 하지만 수술을 통한 병변의 제거 \\ This is an Open Access article distributed under the terms of the Creative Commons \\ Attribution Non-Commercial License (http://creativecommons.org/licenses/by-nc/4.0) \\ which permits unrestricted non-commercial use, distribution, and reproduction in any \\ medium, provided the original work is properly cited.
}

후에도 여전히 음성장애를 호소하는 경우가 있으며 Shin 등ㄹ 의 보고에 따르면 술 후 2 개월이 지나서도 약 $5 \%$ 의 환자에서 음성장애가 지속되었다. 수술 후 지속되는 음성 문제는 애성, 낮은 음도, 무력성, 과도한 노력 발성 등이 있다.2) 또한 후두 미세수술을 받은 성대결절 환자들을 장기간 추적한 결과 음 성치료를 받지 않은 환자의 $56 \%$ 에서 음성장애가 재발했으 며 수술 후 음성치료를 받은 환자에서는 $22 \%$ 에서 재발할 정 
도로 유의하게 재발 확률이 낮아지므로 술 후 음성치료가 필 요하다고 보고하였다. ${ }^{3)}$

후두미세수술 후 음성치료는 수술 부위의 회복을 돕고 재 발 가능성을 낮추며 최적의 음성산출을 돕는 데에 효과적이 라고 알려져 있다. ${ }^{3,4)}$ 후두미세수술 후 음성치료의 필요성과 방법, 기간에 대한 결정을 위해 언어치료사에게 의뢰되며, 음 성치료의 횟수는 질환의 심각성 정도, 시간적·경제적 사정, 그리고 음성치료에 대한 개인적 호응도에 따라 다양하다. ${ }^{4)}$ 그 럼에도 불구하고 후두미세수술을 받은 환자에 대한 음성 예 후나 치료계획 설정을 위한 객관적 근거나 표준지침이 확립되 어 있지 않은 실정이다."

본 연구는 후두미세수술 환자의 수술 전, 수술 후 첫 음성치 료 전, 수술 후 첫 음성치료 후 음질을 청지각적 및 음향분석 을 통해 평가하였고 성대질환 유형, 수술 후 음성치료 기간 및 횟수를 비교 분석하여 후두미세수술 후 음성의 예후와 음성 치료의 필요성 및 방법, 기간 및 횟수에 대한 결정을 위한 객 관적 증거를 얻고자 하였다.

\section{대상 및 방법}

\section{대 상}

2014년 9월부터 2017년 1월까지 성대질환으로 후두미세수 술을 받은 환자 중 수술 전 후 1 개월 내에 음성분석과 음성치 료를 받은 환자 109명을 대상으로 하였다(IRB No. 2018-01-

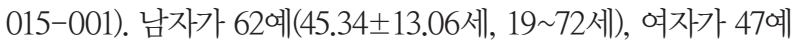
(45.70 \pm 13.09 세, 18 79세)였다. 질환별 환자 분포는 성대용 종 77예, 성대낭종 13예, 성대결절 7예, 라인케부종 5예, 백반 증 및 초기 성문암과 유두종 7예였다(Table 1). 성대용종이 나 성대결절 그리고 성대낭종은 겸자나 가위 등 미세수술도 구를 이용하여 수술하였다. 라인케부종은 내부물질을 흡인 제거하고 여분의 성대점막을 제거하는 방식으로 수술하였고 레이저가 필요한 경우 이용하였다. 후두유두종, 백반증, 조기 성문암은 레이저가 이용하여 수술하였고 병변의 범위에 따 라 절제 정도를 결정하였다.

Table 1. Demographic characteristics of the patients

\begin{tabular}{lccc}
\hline \multicolumn{1}{c}{ Diagnosis } & $\begin{array}{c}\text { Male } \\
(\mathrm{n}=62)\end{array}$ & $\begin{array}{c}\text { Female } \\
(\mathrm{n}=47)\end{array}$ & $\begin{array}{c}\text { Total } \\
(\mathrm{n}=109)\end{array}$ \\
\hline Vocal polyp & 43 & 34 & 77 \\
Vocal cyst & 8 & 5 & 13 \\
Vocal nodule & 2 & 5 & 7 \\
Reinke's edema & 3 & 2 & 5 \\
Early glottic cancer & 3 & 0 & 3 \\
Leukoplakia & 3 & 0 & 3 \\
Laryngeal papillomatosis & 0 & 1 & 1 \\
\hline
\end{tabular}

\section{음성분석 및 수술 후 음성치료}

음성분석에 사용된 음성샘플은 수술 전(preoperative voice analysis, VA0), 수술 후 첫 음성치료 전(postoperative voice analysis, VA1) 수술 후 첫 음성치료 후(postoperative voice analysis after first voice therapy, VA2)에 환자에게 모음 /아/ 를 편안하게 발성하도록 지시하고 Computerized Speech Lab (CSL ${ }^{\mathrm{TM}}$; Model 4500, KayPENTAX, Lincoln Park, NJ, USA) 으로 표본추출률 $44.1 \mathrm{kHz}, 16$ bit 양자화하여 수집된 것이 었다. 수집된 음성샘플에 대하여 청지각적 분석과 음향분석 을 시행하였다.

수술 후 음성분석(VA1)과 첫 음성치료, 첫 음성치료 후 음 성분석(VA2)은 수술 후 평균 8.33⒈92일(6 15일)에 시행하 였다. 수술 후 첫 음성치료는 음성위생 및 적절한 발성에 대 해 설명하고 환자의 발성 특성에 따라 후두마사지, 성도개방 및 후두위치보정, 함수접근법, 반폐성도기법 등과 같은 여러 가지 치료기법을 적용하는 직접치료를 시행하였다. 첫 음성 치료에서 적절한 발성방법을 습득하지 못한 환자는 1 2주 간격으로 음성치료를 지속하였으며 음성치료 기간은 1 9주, 음성치료 횟수는 1 8회로 다양하였다.

청지각적 분석으로는 언어치료사 1 명(1급 자격소지, 음성장 애 관련 임상경력 15년 이상)이 모음연장발성 샘플에 대하여 GRBAS scale(4점 척도)로 음질비정상정도(grade, G), 조조성 정도(roughness, R), 기식성정도(breathiness, B), 긴장성정도 (strain, S)를 측정하였으며 측정 재측정을 통해 평가자 내 신 뢰도를 구하였다. 본 연구에서는 GRBAS 척도 중 무력성 척도 (asthenia, A)를 포함시키지 않았다. 청지각적 평가로 가장 널 리 사용되는 방법인 일본의 GRBAS 척도와 미국의 Consensus Auditory-Perceptual Evaluation of Voice(CAPE-V)는 $\mathrm{GRBS}$ 에 해당하는 척도를 공통으로 가지고 있으나 CAPE$\mathrm{V}$ 에서는 $\mathrm{A}$ 를 측정하지 않고 부가적인 특성에 포함시키고 있 다. $\mathrm{A}$ 척도는 음성의 약함에 대한 척도로 근무력증이나 기력 저하 시 주로 나타나며 구조적 음성장애에서는 일반적으로 드물게 나타나며 기식성과 매우 관련이 높고 GRB 척도에 비 해 타당성이 낮으므로 유럽의 $\mathrm{RBH}$ 분류체계에서도 $\mathrm{A}$ 를 청 지각적 평가에 포함시키지 않고 있다. ${ }^{6)} \mathrm{GRBS}$ 각 척도에 대한 평가자 내 신뢰도는 스피어만상관계수(Spearman correlation coefficient)가 0.831 0.967로 모두 유의하였다.

음향분석은 Multi-Dimensional Voice Program(MDVP ${ }^{\mathrm{TM}}$; KayPENTAX)과 Analysis of Dysphonia in Speech and Voice(ADSV ${ }^{\mathrm{TM}}$; KayPENTAX, Montvale, NJ, USA)를 사 용하여 다양한 음향지표를 산출하였다. MDVP로는 기본주 파수(fundamental frequency, $\mathrm{F}_{0}$ ), 단구간 주파수 변동률 (\%Jitt), 단구간 진폭 변동률(\%Shim), 장구간 주파수 변동률 
(fundamental frequency variation, $\mathrm{vF}_{0}$ ), 장구간진폭변동률 (smoothed amplitude perturbation quotient, sAPQ)을 분석 하였다. ADSV로는 켑스트럼 정점 현저성(cepstral peak prominence, CPP), 켑스트럼/스펙트럼 발성장애 지수(cepstral/ spectral index of dysphonia, CSID)를 분석하였다.

\section{통계분석}

통계분석은 SPSS version 17(SPSS Inc., Chicago, IL, USA)을 이용하였다. 전체 대상자 및 성대질환별로 VA0, VA1, $\mathrm{VA} 2$ 를 비교하기 위하여 반복측정분산분석(repeated ANOVA) 을 하였다.

후두미세수술 후 음성치료 횟수별 음성 특성을 VA0, VA1, VA2 별로 비교하기 위하여 일원분산분석(one-way ANOVA) 을 하였다. 그리고 술 후 4회 이상의 음성치료를 요하는 환자 에 대한 예측지표를 찾기 위하여 receiver operating characteristic(ROC) 커브 분석을 하였다.

\section{결 과}

\section{VA0, VA1, VA2 음질 비교}

\section{청지각적 평가}

전체 환자를 대상으로 한 평균비교 결과 GRBS 모든 지표 가 VA0에 비해 VA1에서 유의하게 좋아졌으며 첫 음성치료 를 통해 VA2에서 유의하게 더 좋은 음성을 산출할 수 있었 다 $(p<0.05$ )(Table 2). 질환별로는 성대용종, 성대낭종, 성대 결절, 라인케부종에서는 $\mathrm{VAO}$ 에 비해 VA1에서 청지각적으로 유의한 개선이나 개선된 경향을 보였고 VA2에서 더 유의한 개선이나 개선된 경향을 보였다. 백반증 및 초기 성문암과 유 두종은 $\mathrm{VA1}$ 에서 조조성(R)만 개선되고 다른 지표들은 더 악 화되는 경향을 보였으나 VA2에서 모든 청지각적 지표가 VA0 과 유사한 정도로 향상된 음질을 산출할 수 있었다(Fig. 1).

Table 2. Auditory perceptual analysis

\begin{tabular}{lcccc}
\hline $\begin{array}{c}\text { Dependent } \\
\text { variable }\end{array}$ & VAO & VA1 & VA2 & $\begin{array}{c}\text { p-value } \\
\text { (post hoc) }\end{array}$ \\
\hline Grade & $1.78 \pm 0.67$ & $1.31 \pm 0.57$ & $0.65 \pm 0.51$ & $<0.001^{a, b, c}$ \\
Roughness & $1.20 \pm 0.85$ & $0.81 \pm 0.73$ & $0.41 \pm 0.49$ & $<0.001^{a, b, c}$ \\
Breathiness & $1.38 \pm 0.80$ & $0.94 \pm 0.68$ & $0.36 \pm 0.56$ & $<0.001^{a, b, c}$ \\
Strain & $1.07 \pm 0.80$ & $0.63 \pm 0.71$ & $0.26 \pm 0.43$ & $<0.001^{a, b, c}$ \\
\hline
\end{tabular}

*adjustment for multiple comparisons: Bonferroni. ${ }^{\circ}$ The difference between VAO and VAl was significant at the $<0.001$ level, 'The difference between VAl and VA2 was significant at the $<0.001$ level, 'The difference between VAO and VA2 was significant at the $<0.001$ level. VAO: preoperative voice analysis, VA 1: postoperative voice analysis, VA2: postoperative voice analysis after first voice therapy

\section{음향학적 평가}

전체 109 명 중 6 명의 음성에서 기본주파수가 검출되지 않 아 103명의 음성에 대해 MDVP로 음성분석을 시행하였고 $\mathrm{ADSV}$ 로는 대상자 전체 109명의 음성에 대해 음성분석을 시행하였다. $\mathrm{F}_{0}$ 는 VA0에 비해 VA1에서 유의한 변화가 없었 으나 VA2에서 유의하게 높아졌다 $(p<0.001)$. 분석된 모든 변 동률지표 $\left(\% \mathrm{Jitt}, \mathrm{vF}_{0}, \% \mathrm{Shim}, \mathrm{sAPQ}\right)$ 가 $\mathrm{VAO}$ 에 비해 $\mathrm{VA} 1$ 에 서 유의하게 낮아졌으며, VA2에서 유의하게 더 낮아졌다 $(p<$ 0.05). CPP는 VA0에 비해 VA1에서 유의하게 높아졌으며, VA2 에서 유의하게 더 높아졌고 CSID는 VA0에 비해 VA1에서 유의하게 낮아졌으며, VA2에서 유의하게 더 낮아졌다 $(p<$ 0.001)(Table 3).

질환별로는 $\mathrm{F}_{0}$ 는 모든 질환이 $\mathrm{VAO}$ 에 비해 VA1에서 유의 한 변화가 없었으나 VA2에서 높아지는 경향을 보였다. 성대 용종은 VA0에 비해 VA1의 모든 음향지표(\%Jitt, \%Shim, $\left.\mathrm{vF}_{0}, \mathrm{sAPQ}, \mathrm{CPP}, \mathrm{CSID}\right)$ 에서 유의한 향상을 보였고 $\mathrm{VA} 2$ 에 서 유의하게 더 향상된 결과를 보였다. 성대낭종은 모든 음향 지표에서 VA0에 비해 VA1, V1보다 VA2에서 더 향상된 경 향을 보였으며 특히 VA2에서 \%Jitt, CPP, CSID가 유의한 향 상을 보였다. 성대결절은 $\mathrm{VAO}$ 에 비해 VA1과 VA2의 음향지 표에서 향상되는 경향을 보였지만 유의한 차이는 없었다. 라 인케부종은 $\mathrm{VAO}$ 에 비해 $\mathrm{VA} 1$ 의 \% Jitt, \% Shim, $\mathrm{vF}_{0}, \mathrm{CPP}$, $\mathrm{CSID}$ 는 향상되고 $\mathrm{SAPQ}$ 는 나빠지는 경향을 보였으나 $\mathrm{VA} 2$ 의 모든 음향지표에서 향상된 경향을 보였다. 백반증 및 초기 성문암과 유두종은 $\mathrm{CPP}$ 와 CSID가 VA0에 비해 VA1에서 유 의하게 나빠졌으나 $(p<0.05)$ 첫 음성치료 후 유의하게 개선되 어 $(p<0.05) \mathrm{VAO}$ 의 음성과 유의한 차가 없는 정도로 개선되었 고 MDVP 음향지표에서도 VA1에서 나빠지고 VA2에서 개선 되는 경향을 보였다(Fig. 2).

\section{술 후 음성치료 횟수에 대한 예측력}

음성치료 기간은 1 9주, 음성치료 횟수는 1 8회로 다양했 다. 질환별 평균 음성치료 횟수는 라인케부종이 1.6회로 가 장적었으며, 성대용종 1.73 회, 성대낭종 2.00 회, 성대결절 2.14회, 백반증 및 초기 성문암과 유두종 2.43회 순으로 높았 으나 통계적으로 유의한 차는 보이지 않았다 $(p=0.489)$.

수술 후 음성치료 횟수에 따라 네 집단(1회, 2회, 3회, 4회 이 상)으로 나누어 VA0, VA1, VA2 음질을 청지각적 음질장애 지표인 G와 음향음질장애지표인 CSID로 비교하였다(Table 4). $\mathrm{VAO}$ 에서는 음성치료 횟수 집단 간에 $\mathrm{G}$ 와 $\mathrm{CSID}$ 는 유의한 차이가 없었다 $(\mathrm{G}, p=0.445 ; \mathrm{CSID}, p=0.955)$. VA1에서는 $\mathrm{G}$ 지 표와 CSID가 음성치료 횟수 집단 간 유의한 차이를 보였으 며 $(p<0.01, p<0.01)$, 음성치료 횟수가 많은 집단일수록 평균 
$\mathrm{G}$ 지표와 CSID가 높은 경향을 보였다. 집단 간 사후검정 결 과 $\mathrm{G}$ 지표는 4회 이상 치료를 받은 집단과 1회의 치료를 받은 집단 간에만 통계적으로 유의한 차이를 보였고, CSID는 4회
이상 음성치료를 받은 집단이 2회 이하의 치료를 받은 집단 들보다 통계적으로 유의하게 높았다 $(p<0.05)$. VA2에서는 음성치료 횟수 집단 간 $\mathrm{G}$ 지표는 유의한 차를 보이지 않았고

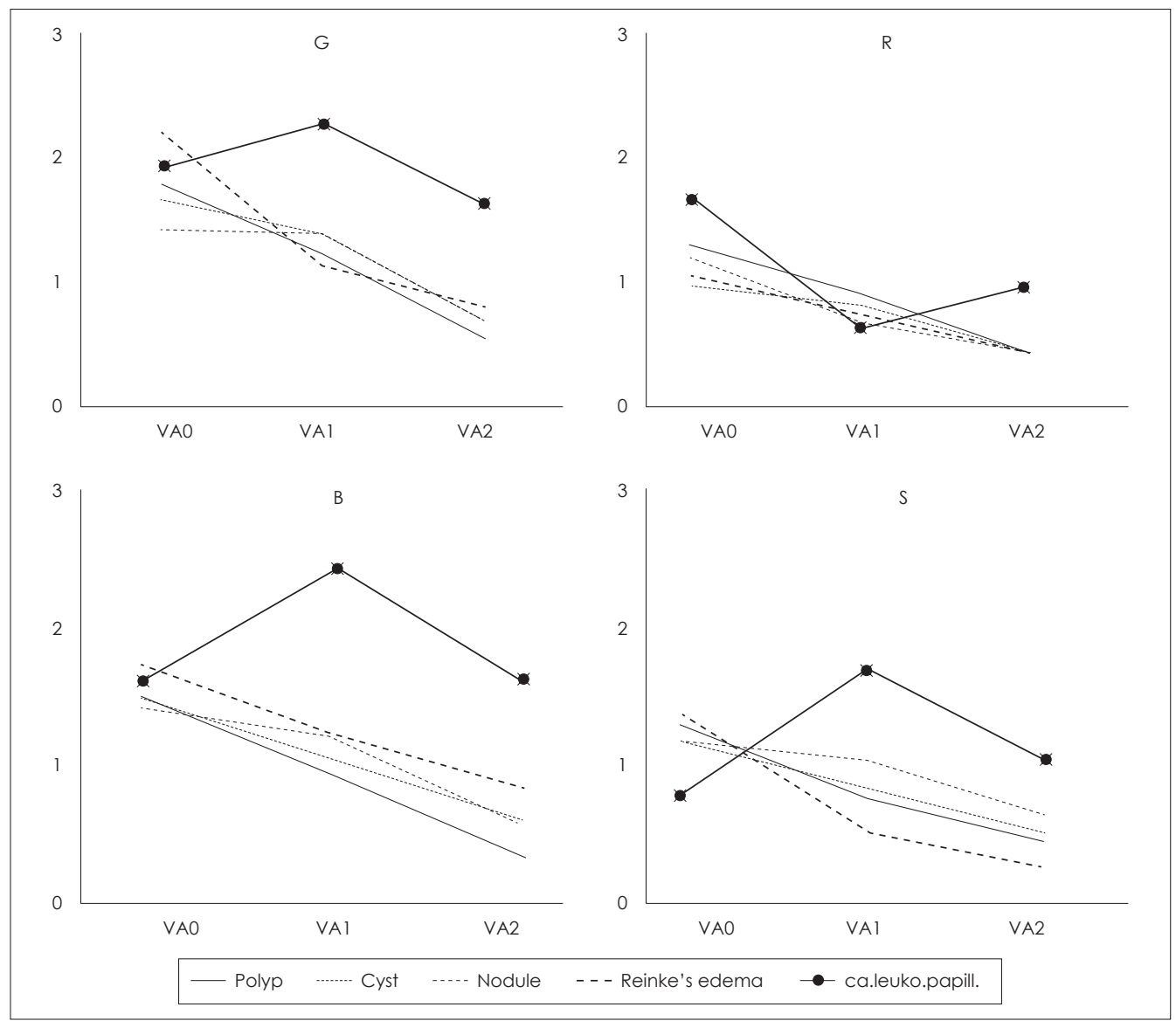

Fig. 1. Auditory perceptual analysis with GRBAS scale. When compared preoperative voice with postoperative voice by vocal fold diseases, postoperative voice was significantly improved in vocal polyp, cyst, nodule and reinke's edema, no significant difference or worse in precancerous lesions, early glottic cancer and laryngeal papillomas. Voice quality improved even more after first postoperative voice therapy. VA0: preoperative voice analysis, VA1: postoperative voice analysis, VA2: postoperative voice analysis after first voice therapy, G: overall grade, R: roughness, B: breathiness, S: strain, ca.leuko.papill.: early glottic cancer, leukoplakia and laryngeal papillomatosis.

Table 3. Acoustic analysis

\begin{tabular}{|c|c|c|c|c|}
\hline Dependent variable & VAO & VAl & VA2 & p-value (post hoc)* \\
\hline $\mathrm{F}_{0}$ & $155.58 \pm 44.19$ & $153.40 \pm 47.18$ & $178.28 \pm 41.54$ & $<0.001^{b, c}$ \\
\hline M & $126.62 \pm 22.97$ & $122.00 \pm 31.90$ & $146.89 \pm 21.39$ & $<0.001^{b, c}$ \\
\hline $\mathrm{F}$ & $193.07 \pm 35.64$ & $192.32 \pm 30.33$ & $217.45 \pm 24.04$ & $<0.001^{\mathrm{b}, \mathrm{c}}$ \\
\hline \% Jitt & $2.77 \pm 2.10$ & $1.73 \pm 1.13$ & $0.87 \pm 0.87$ & $<0.001^{a, b, c}$ \\
\hline \%Shim & $6.85 \pm 4.80$ & $3.80 \pm 2.61$ & $3.08 \pm 2.04$ & $<0.001^{a, b, c}$ \\
\hline $\mathrm{vF}_{0}$ & $6.64 \pm 10.71$ & $2.30 \pm 3.06$ & $1.18 \pm 1.09$ & $<0.001^{a, b, c}$ \\
\hline SAPQ & $6.98 \pm 4.34$ & $4.45 \pm 2.60$ & $3.48 \pm 1.94$ & $<0.001^{a, b, c}$ \\
\hline CPP & $9.44 \pm 3.64$ & $11.15 \pm 2.99$ & $13.48 \pm 2.54$ & $<0.001^{a, b, c}$ \\
\hline CSID & $35.65 \pm 2.98$ & $16.97 \pm 2.32$ & $5.72 \pm 1.73$ & $<0.001^{a, b, c}$ \\
\hline
\end{tabular}

*adjustment for multiple comparisons: Bonferroni method. ${ }^{\circ}$ The difference between VAO and VAl was significant at the $<0.001$

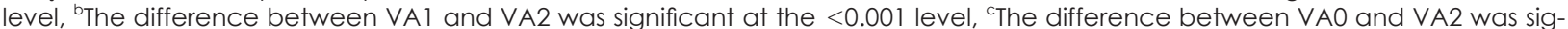
nificant at the $<0.001$ level. VA0: preoperative voice analysis, VA1: postoperative voice analysis, VA2: postoperative voice analysis after first voice therapy, $F_{0}$ : fundamental frequency, $M$ : male, $F$ : female, $\mathrm{VF}_{0}$ : fundamental frequency variation, sAPQ: smoothed amplitude perturbation quotient, CPP: cepstral peak prominence, CSID: cepstral spectral index of dysphonia 
$(p=0.127), \operatorname{CSID}$ 지표는 음성치료 횟수 집단 간 유의한 차이 를 보였으며 $(p<0.01)$, 음성치료 횟수가 많은 집단일수록 평 균 CSID가 더 높았으나 집단 간 사후검정결과 4회 이상 음성
치료를 받은 집단만이 3 회 이하의 음성치료를 받은 집단들 보다 유의하게 높았다 $(p<0.01)$ (Tables 4 and 5).

술 후 4 회 이상 여러 차례 음성치료가 필요한 환자를 가장

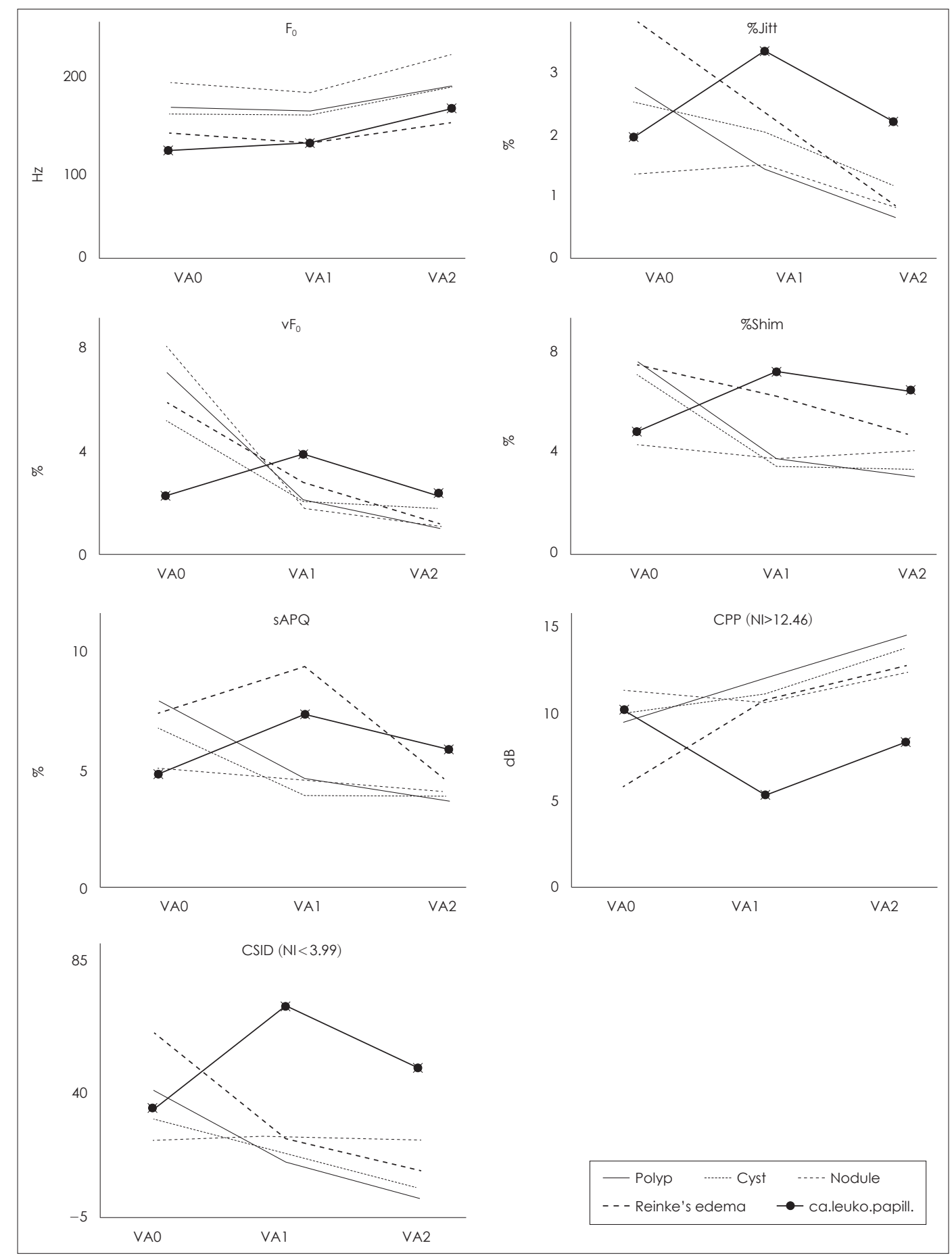

Fig. 2. Acoustic analysis. $F_{0}$ was not significantly changed after laryngeal microsurgery, but it tended to increase after first postoperative voice therapy. Multi-dimensional voice program parameters (\%Jitt, \%Shim, vF $\left.F_{0}, s A P Q\right)$ showed a tendency of decrease in VA2 compared to VA1. CPP was increased and CSID was decreased in VA2, which indicating improvement of voice quality after postoperative voice therapy. VA0: preoperative voice analysis, VA1: postoperative voice analysis, VA2: postoperative voice analysis after first voice therapy, $F_{0}$ : fundamental frequency, $\mathrm{FF}_{0}$ : fundamental frequency variation, $\mathrm{SAPQ}$ : smoothed amplitude perturbation quotient, CPP: cepstral peak prominence, CSID: cepstral spectral index of dysphonia, ca.leuko.papill.: early glottic cancer, leukoplakia and laryngeal papillomatosis, NI: normal index. 
Postoperative Voice Therapy I Seo IH, et al.

Table 4. Voice quality measured by Grade of auditory perceptual analysis according to number of voice therapy

\begin{tabular}{lccc}
\hline $\begin{array}{c}\text { No. of voice } \\
\text { therapy (patients) }\end{array}$ & VAO & VAl & VA2 \\
\hline $1(n=53)$ & $1.67 \pm 0.68$ & $1.17 \pm 0.49$ & $0.55 \pm 0.53$ \\
$2(n=35)$ & $1.86 \pm 0.68$ & $1.34 \pm 0.58$ & $0.69 \pm 0.57$ \\
$3(n=12)$ & $1.83 \pm 0.72$ & $1.42 \pm 0.51$ & $0.75 \pm 0.58$ \\
$\geq 4(n=9)$ & $2.00 \pm 0.87$ & $1.89 \pm 0.93$ & $1.00 \pm 0.66$ \\
p-value (post hoc)* & 0.445 & $0.006^{a}$ & 0.127 \\
\hline
\end{tabular}

*adjustment for multiple comparisons: Tukey-Kramer method. ${ }^{a}$ The difference between 1 and $\geq 4$ was significant at the $<0.01$ level. VA0: preoperative voice analysis, VA1: postoperative voice analysis, VA2: postoperative voice analysis after first voice therapy

Table 5. Voice quality measured by cepstral spectral index of dysphonia according to number of voice therapy

\begin{tabular}{lccr}
\hline $\begin{array}{c}\text { No. of voice } \\
\text { therapy (patients) }\end{array}$ & VAO & VAl & VA2 \\
\hline $1(n=53)$ & $34.8 \pm 29.5$ & $12.1 \pm 14.9$ & $3.2 \pm 12.9$ \\
$2(n=35)$ & $36.9 \pm 25.9$ & $14.9 \pm 24.3$ & $5.2 \pm 18.0$ \\
$3(n=12)$ & $33.0 \pm 32.0$ & $26.0 \pm 26.2$ & $5.1 \pm 16.1$ \\
$\geq 4(n=9)$ & $39.3 \pm 45.1$ & $41.5 \pm 37.4$ & $23.2 \pm 29.0$ \\
p-value (post hoc)* & 0.955 & $0.002^{a, b}$ & $0.014^{\text {a,b,c }}$ \\
\hline
\end{tabular}

*adjustment for multiple comparisons: Tukey-Kramer method. ${ }^{a}$ The difference between 1 and $\geq 4$ was significant at the $<0.01$ level, ${ }^{b}$ The difference between 2 and $\geq 4$ was significant at the $<0.05$ level, 'The difference between 2 and $\geq 4$ was significant at the $<0.05$ level. VA0: preoperative voice analysis, VAl: postoperative voice analysis, VA2: postoperative voice analysis after first voice therapy

잘 예측할 수 있는 지표를 알아보기 위해 $\mathrm{VAO}, \mathrm{VA} 1, \mathrm{VA} 2$ 의 $\mathrm{G}$ 지표와 CSID에 대한 ROC 커브를 분석하였다(Table 6). 술 후 첫 음성치료 후 CSID가 5.88 초과일 때 area under the curve 면적이 0.78 로 가장 높은 예측력을 보였으며 민감도는 $100 \%$, 특이도는 68\%였다(Fig. 3).

\section{고 찰}

음성은 성대의 진동으로 형성된 후두 음원이 성도의 긴장 도나 모양에 따른 공명에 의해 산출되는 소리이므로 음성은 발성기관의 구조 신경학적 상태뿐만 아니라 호흡과 발성, 공 명 등의 기능적 사용방법 및 습관에 의해 결정된다. ${ }^{7}$ 본 연구 결과 술 후 청지각적 지표(GRBS)와 음향학적 지표 $\% \mathrm{Jitt}, \mathrm{vF}_{0}$, $\% \mathrm{Shim}, \mathrm{sAPQ}, \mathrm{CPP}, \mathrm{CSID})$ 가 유의하게 좋아졌음에도 불구 하고 전체 대상자 중 49.5\%(109명 중 54명)만이 음질의 비정 상정도(G)가 낮아졌으며 38.5\%(109명 중 42명)는 변화가 없었 고 $11.9 \%$ (109명 중 13명)는 수술 후 음질의 비정상정도가 더 심해졌다. 후두미세수술은 성대 병변에 대한 제거로 성대, 즉 음원부에 국한된 구조적 개선을 통한 음성 기능 회복과 보존 에 효과적이지만 수술을 통한 성대 병변의 제거와 수술 부위
Table 6. Comparison of receiver operating characteristic curves

\begin{tabular}{cc}
\hline & AUC $(95 \% \mathrm{Cl})$ \\
\hline VA0 & $0.57 \pm 0.12(0.47-0.66)$ \\
$G$ & $0.53 \pm 0.10(0.44-0.63)$ \\
CSID & $0.68 \pm 0.10(0.58-0.77)$ \\
VAl & $0.77 \pm 0.08(0.68-0.85)$ \\
$G$ & \\
CSID & $0.66 \pm 0.08(0.56-0.75)$ \\
VA2 & $0.78 \pm 0.05(0.69-0.85)$ \\
G & \\
CSID &
\end{tabular}

VA0: preoperative voice analysis, $\mathrm{VAl}$ : postoperative voice analysis, VA2: postoperative voice analysis after first voice therapy, Cl: confidence interval, G: overall grade, CSID: cepstral spectral index of dysphonia

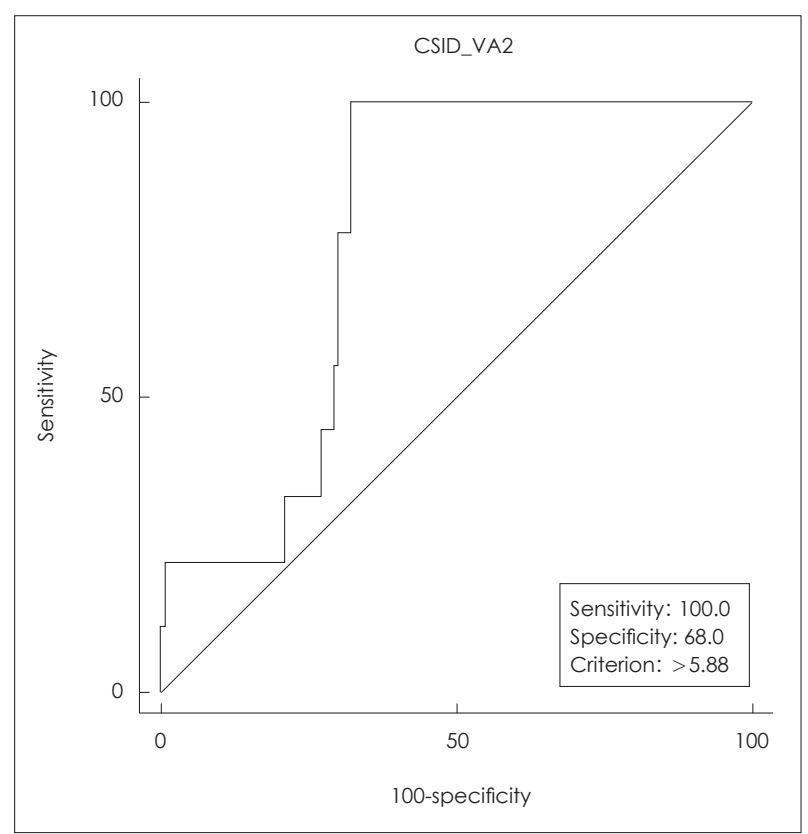

Fig. 3. Receiver operating characteristic curves. When the CSID was 5.88 or higher after first postoperative voice therapy, the area under the curve area showed the highest predictive power of 0.78 , with a sensitivity of $100 \%$ and a specificity of $68 \%$. CSID: cepstral spectral index of dysphonia, VA2: postoperative voice analysis after first voice therapy.

의 회복 후에도 음성장애가 지속될 수 있다.2,3,5,8-10) 수술 후 많 은 환자들이 음성사용에 대한 염려와 음성휴식 후 음성사용 재개에 대한 부적응으로 부적절한 보상발성을 하거나 수술 전 오랫동안 지속되었던 부적절한 발성습관 때문인 것으로 보인다.

수술 후 음성치료는 적절한 호흡, 발성, 공명 조절 능력 향 상을 통한 최적의 음성산출을 돕기 위해 시행된다. $23,5,8)$ 수술 후 첫 음성치료는 술 후 환자의 음질 및 발성방법과 음성위 생 및 적절한 발성에 대해 설명 및 교육을 하는 간접치료와 부적절한 보상발성 제거 및 최적의 발성을 탐색하기 위한 여 
러 가지 치료기법을 적용하는 직접치료를 시행한다. 본 연구 결과 전체 대상자 중 69.7\%(109명 중 76명)가 수술 후 음성에 비해 첫 음성치료 후 음질비정상정도가 낮아졌다. 이러한 결 과는 후두미세수술 후 음성치료가 다양한 성대질환에서 더 좋은 음성산출방법을 찾는 데에 효과적임을 보여준다.

성대점막이나 성대점막하 질환인 성대용종, 성대낭종, 성대 결절, 라인케부종에서는 VA0에 비해 VA1과 VA2에서 개선되 는 경향을 보인 반면 백반증 및 초기 성문암과 유두종은 VA1 에서 조조성(R)을 제외한 모든 청지각지표와 음향지표에서 더 악화되는 경향을 보였다. 이러한 결과는 백반증 및 초기 성문암과 유두종이 질환의 범위가 근육층까지 침범됨으로 인해 수술 범위가 다른 군에 비해 깊었기 때문인 것으로 보인 다. 또한 백반증 및 초기 성문암과 유두종은 VA2에서 VA0 와 유사한 정도로 향상된 음성을 산출할 수 있었는데 이 결 과는 이러한 환자들에 있어서도 수술 후 음성관리가 필요함 을 보여준다.

$\mathrm{MDVP}$ 의 단구간 변동률(\% $\mathrm{Jitt}, \% \mathrm{Shim})$ 과 장구간 변동률 $(\mathrm{vF}, \mathrm{sAPQ})$, 켑스트럼/스펙트럼 음향지표들(CPP, CSID)은 후두미세수술 전후 음질 변화의 다양한 측면을 객관적으로 알아봄에 있어서 유용하다. ${ }^{911-14)}$ 본 연구결과는 이러한 음향 지표들이 수술 후 음성치료결과 측정과 적절한 발성에 대한 객관적 확인과 피드백 제공에도 유용함을 보여준다.

성대질환은 정상성대보다 성대의 질량을 증가시키거나 성 대진동을 감소시키므로 $\mathrm{F}_{0}$ 가 낮아지게 한다. ${ }^{15)}$ 수술을 통한 병변 제거와 수술 부위의 회복 후 $\mathrm{F}_{0}$ 가 높아질 것으로 기대 했으나 본 연구결과 $\mathrm{F}_{0}$ 는 술 전에 비해 술 후 통계적으로 유 의한 차를 보이지는 않았지만 오히려 낮아졌으며 이러한 결 과는 선행연구들에서도 동일하게 보고되었다. ${ }^{19,14)}$ 술 후 유의 한 차 없이 낮아졌던 $\mathrm{F}_{0}$ 는 첫 음성치료결과 유의하게 높아졌 으며 술 전에 비해서도 유의하게 높았다. 수술 후 지속되는 음성 문제 중의 하나인 부적절하게 낮은 음도로 보상 발성하 는 음성오용의 문제가 술 후 음성치료의 중요한 치료목표이 며 음질개선에 도움이 될 수 있다. 2,16$)$ 다만 남성의 경우 $\mathrm{F}_{0}$ 가 약간 높게 측정되었다. 이러한 부분은 검사시기 간에 동일한 조건이 아닐 수 있어, 음성 분석 연구의 한계로 생각된다.

본 연구에 참여한 성대질환 유형별 대상자 수가 5 명에서 77 명까지 다양하여 집단별 VA0, VA1, VA2 비교나 집단 간 통계적 유의성을 확인·해석하기에는 여러가지 제한점이 있 지만 성대질환 유형별 경향을 알아보고 후속연구의 필요성 을 찾는 데에 의미가 있을 것으로 보인다. 성대낭종과 성대결 절 모두 VA2에서 기식성(B)과 음질의 비정상정도 $(\mathrm{G})$ 가 청지 각적으로는 개선되었으나 이와 상관이 높은 음향학적 지표인 $\%$ jitt, CPP, CSID는 성대낭종에서만 유의한 차이를 보였고
성대결절은 향상된 경향만 보이고 유의한 차이를 보이지 못 했다. 이러한 현상은 성대결절 환자들의 잘못된 발성습관은 일반적으로 한 번의 시도치료로는 유의한 변화를 보이지 못 할 정도로 고착되어 있기 때문인 것으로 생각된다. 라인케부 종 환자(5명)의 $\mathrm{SAPQ}$ 평균은 $\mathrm{VAO}$ (7.18)에 비해 $\mathrm{VA1}(8.23)$ 에 서 나빠졌으나 각 환자별 변화를 살펴보면 실제로 나빠진 사 례는 1명(VA0; 2.96, VA1; 16.87)뿐이었으며 5명 중 4명은 향 상되었다. 집단별 평균 치료 횟수가 1.6명에서 2.43회로 큰 차 이를 보이지 않았으며 4 회 이상의 치료를 받은 환자에는 라인 케부종을 제외한 모든 질환군의 환자들(성대결절 2 명, 성대 용종 5명, 성대낭종 1 명, 초기 성문암 1명)이 포함되었다. 이러 한 결과들이 일반적인 현상인지 객관적으로 검증하기 위해 각 성대질환 유형별 수술 후 장기간 예후 및 음성치료 이행에 대한 후속연구가 필요할 것으로 보인다.

$\mathrm{G}$ 척도는 전반적 음질비정상정도를 나타내며 청지각적 평 가법인 GRBAS 척도 중 평가자 간 신뢰도가 가장 높고 CSID 는 $\mathrm{G}$ 척도와 가장 상관관계가 높은 객관적 음향지표로 비정 상적인 음질을 정확하고 타당하게 감별할 수 있다.,12) 술 후 음성예후와 4회 이상의 지속적인 치료를 요하는 환자에 대한 예측지표를 찾기 위하여 음성치료 횟수 집단 간 $\mathrm{VAO}, \mathrm{VA} 1$, $\mathrm{VA} 2$ 음질을 $\mathrm{G}$ 척도와 $\mathrm{CSID}$ 로 비교한 결과 VAO에서는 두 지표 모두가 음성치료 횟수 집단 간에 유의한 차를 보이지 않 았다. VA1과 VA2의 CSID가 음성치료 횟수 집단 간 유의한 차를 보인 반면 $\mathrm{G}$ 척도는 $\mathrm{VA} 1$ 에서만 유의한 차를 보일 뿐 $\mathrm{VA} 2$ 에서는 치료 횟수가 많을수록 $\mathrm{G}$ 척도가 높았으나 유의 한 차는 없었다. 이러한 이유는 $\mathrm{G}$ 척도는 4점 척도로 측정되 므로 작은 음질의 변화에는 민감하지 못하기 때문이다. ${ }^{12)}$

4회기 이상의 지속적인 음성치료를 받은 환자들 모두는 첫음성치료 후에도 G와 CSID가 각각 1과 5.88 이상으로 정상 음질을 산출할 수 없었던 환자들로서 지속적인 음성치료를 필요로 했던 환자들이었다. 음성치료를 필요로 하는 준거로 음질은 중요한 기준이 된다. 음질의 비정상정도 및 장기간의 음성치료와 관리를 요하는 환자들의 선별 및 치료계획을 위 한 객관적인 기준으로 $\operatorname{CSID}(\geq 5.88)$ 가 사용될 수 있을 것으로 생각된다.

결론적으로 술 후 음성치료는 후두미세수술 환자들이 더 좋은 음성산출방법을 찾는 데에 도움이 되며, 술 후 음성분 석이 지속적인 음성치료를 필요로 하는 환자의 선별에 도움 이 될 것으로 사료된다.

\section{REFERENCES}

1) Shin YS, Chang JW, Yang SM, Wu HW, Cho MH, Kim CH. Persistent dysphonia after laryngomicrosurgery for benign vocal fold disease. Clin Exp Otorhinolaryngol 2013;6(3):166-70. 
2) Wang NM, Huang TS. [A vocal treatment plan for voice disorders after phonosurgery--a preliminary study]. Changgeng Yi Xue Za Zhi 1994;17(2):144-8

3) Béquignon $E$, Bach C, Fugain C, Guilleré L, Blumen M, Chabolle F, et al. Long-term results of surgical treatment of vocal fold nodules. Laryngoscope 2013;123(8):1926-30.

4) Petrovic-Lazic M, Jovanovic N, Kulic M, Babac S, Jurisic V. Acoustic and perceptual characteristics of the voice in patients with vocal polyps after surgery and voice therapy. J Voice 2015;29(2):241-6.

5) Kaneko M, Shiromoto O, Fujiu-Kurachi M, Kishimoto Y, Tateya I, Hirano S. Optimal duration for voice rest after vocal fold surgery: randomized controlled clinical study. J Voice 2017;31(1):97-103.

6) Wendler J, Rauhut A, Krüger H. Classification of voice qualities. J Phonet 1986;14:483-8.

7) Fant G. Acoustic theory of speech production: with calculations based on X-ray studies of Russian articulations. The Hague: Mouton;1970.

8) Lin L, Sun N, Yang Q, Zhang Y, Shen J, Shi L, et al. Effect of voice training in the voice rehabilitation of patients with vocal cord polyps after surgery. Exp Ther Med 2014;7(4):877-80.

9) Seo IH, Jung D, Han HJ, Moon JH, Chung PS, Lee SJ. Analysis of acoustic parameters to objectively reflect the change of voice quality before and after surgery in benign vocal fold mucosal disorders. Korean J Otorhinolaryngol-Head Neck Surg 2016;59(11):775-9.

10) Baek MJ, Hwang BH, Wang SG. Prediction of postoperative voice by speech synthesis in benign laryngeal diseases. Korean J OtolaryngolHead Neck Surg 2002;45(3):279-84.

11) Uloza V, Saferis V, Uloziene I. Perceptual and acoustic assessment of voice pathology and the efficacy of endolaryngeal phonomicrosurgery. J Voice 2005;19(1):138-45.

12) Nemr K, Simões-Zenari M, Cordeiro GF, Tsuji D, Ogawa AI, Ubrig MT, et al. GRBAS and Cape-V scales: high reliability and consensus when applied at different times. J Voice 2012;26(6):812.e17-22.

13) Park SH, Lee SG, Cho NS, Lee MJ, Lee BD, Chang HS, et al. A study for changes of acoustic parameters between pre and postoperative voice in laryngeal nodule and polyp. Korean J Otolaryngol-Head Neck Surg 1999;42(5):634-8.

14) Nam SY, Park JH, Jeon HG, Kim SY. Acoustic analysis of benign vocal cord lesions: before and after microlaryngeal surgery. Korean J Otolaryngol-Head Neck Surg 1998;41(7):925-8.

15) Zeitels SM, Casiano RR, Gardner GM, Hogikyan ND, Koufman JA, Rosen CA; Voice and Swallowing Committee, American Academy of Otolaryngology-Head and Neck Surgery. Management of common voice problems: committee report. Otolaryngol Head Neck Surg 2002; 126(4):333-48.

16) Van Lierde KM, Claeys S, De Bodt M, van Cauwenberge P. Long-term outcome of hyperfunctional voice disorders based on a multiparameter approach. J Voice 2007;21(2):179-88. 